\title{
Proteomic analysis of subarachnoid hemorrhage - liquid-phase isoelectric focusing in complex protein sample
}

\author{
Joanna Hajduk', Bartosz Sokół², Agata Swiatly', Jan Matysiak', Piotr Nowicki', \\ Ewa Garbiec ${ }^{1}$, Norbert Wąsik ${ }^{2}$, Roman Jankowski ${ }^{2}$, Zenon J. Kokot ${ }^{1}$ \\ ${ }^{1}$ Department of Inorganic and Analytical Chemistry, Poznan University of Medical Sciences, Poland \\ ${ }^{2}$ Department of Neurosurgery, Poznan University of Medical Sciences, Poland
}

\begin{abstract}
Aim. The aim of this study was to present the proteomic approach based on liquid phase isoelectric focusing fractionation coupled to nLC-MALDI-TOF/TOF-MS/MS analysis to characterize cerebrospinal fluid from control patients and those suffering from subarachnoid hemorrhage. The new perspective in characterization of this brain neuropathology is in constant demand to point a valuable panel of indicators which could improve the treatment outcome.

Material and Methods. The cerebrospinal fluid samples were applied to a commercial liquid phase isoelectric focusing apparatus and separated into 10 fractions by pl. Further, the untargeted mass spectrometry investigations were performed with data dependent acquisition mode for full-scan MS analysis with subsequent MS/MS fragmentation using nLC-MALDI-TOF/TOF-MS/MS.

Results. In total, the detection of 1664 and 2187 unique tryptic peptides provided biological evidence for 134 and 271 proteins in control and subarachnoid hemorrhage sample, respectively. The interpretation of liquid phase separation was performed by intersection analysis of two items between groups of ten fractions. The cumulative intersection exploration revealed the highest concentration of the detected components in the middle fractions of the focusing chamber, whereas the gradual dilution appeared on its extreme.

Conclusions. The employed strategy ensured overall screening of investigated material presenting the proteins abundance in the current state of analysis. Few proteins such as proenkephalin A, peroxiredoxin- 6 , cathepsin B, thrombospondin-1, glial fibrillary acidic protein and $\alpha$-spectrin were recognized as potential indicators, according to literature, pointing the possibility for monitoring in further studies as panel of valuable biomarkers.
\end{abstract}

Keywords: MALDI mass spectrometry, proteomic strategies, protein separation, cerebrospinal fluid, subarachnoid hemorrhage.

\section{Introduction}

Cerebrospinal fluid (CSF) surrounds the central nervous system including the ventricular system of the brain, spinal canal and subarachnoid space cranial cavity. It is produced by choroid plexus of the brain cells, lining cells and microglia [1]. The main functions of the CSF are the protection of the brain and spinal cord from the mechanical injuries, compensation of the intracra- nial pressure and transfer of the humoral information. Analysis of this fluid may access the state of the environment in human central nervous system (CNS) [2].

Aneurysmal subarachnoid hemorrhage (SAH) belongs to cerebrovascular diseases and contributes to $6-8 \%$ of all cerebral stroke events. It is caused by the extravasation of blood into the sub-arachnoid space [3]. The pathophysiological process of cellular and molecu- 
lar changes following SAH are still not fully characterized [4]. Therefore, the proteomic examination of CSF may contribute to detection of potential cerebral indicators, which will lead to better prediction of patients deterioration and treatment outcome [3, 5-6]. Currently performed proteomic analyses are mostly based on mass spectrometry (MS) with application of soft ionization methods: MALDI (matrix-assisted laser desorption/ ionization) and ESI (electrospray ionization). Due to significant specificity and sensitivity, these techniques are commonly used in numerous clinical studies e.g. monitoring of selected compounds [7]. However, direct analysis of complex biological samples is associated with problems of analyte suppression and high dynamic range in protein content $[8,9]$. Thus, the preparation steps including separation and concentration of analyzed sample are often required before MS analysis.

Cerebrospinal fluid suffers protein dynamic range problems with the small number of proteins constituting the sample. Preparation techniques are important in order to identify the largest number of constituents and thus appropriate biomarker within sample. One of the widely used method is two dimensional gel electrophoresis (2-DE), which combines two independent separation processes: due to isoelectric point and molecular weight of proteins [10]. Its compatibility with mass spectrometry techniques is defined as bottom-up strategy in clinical proteomic research [11].

An alternative approach to gel electrophoresis in modern proteomics is fractionation based on gel free liquid phase isoelectric focusing (LP-IEF) [12], where the protein charge is changing until its $\mathrm{pl}$ is reached. By adding carrier ampholytes [13], smooth and relatively stable $\mathrm{pH}$ gradient with greater buffering capacity could be achieved. Moreover, the main advantage of gel free technology is associated with the possibility of protein recovery in the liquid phase [14]. Therefore, this methodology becomes an attractive tool as a separation technique prior to the nano-LC/MS analysis, widely applied into various biological samples like a human erythroleukemia cell line [15], ovarian carcinoma cells [16-17] or brain tissue [18]. Regarding to our study, LP-IEF in combination with gel electrophoresis was reported to be an important tool for identifying low abundant proteins in human cerebrospinal fluid and membrane proteins in frontal cortex [19].

\section{Aim}

The aim of this study was to present method for proteomic analysis of CSF for screening analysis of SAH.
We used LP-IEF combined with nLC-MALDI-TOF/TOF mass spectrometry to characterize the protein content of analyzed cases with and without SAH. The usefulness of gel free strategy was estimated by intersection analysis.

\section{Material and Methods}

\section{Study cases}

The research project has been approved by the Regional Ethics Committee of the Poznan University of Medical Sciences (decision No. 503/15). The SAH case was admitted due to the subarachnoid hemorrhage. A computed tomography (CT) scan demonstrated intracerebral hemorrhage of the left frontal lobe and intraventricular bleeding causing mass effect (Figure 1). Digital subtraction angiography demonstrated ruptured anterior communicating artery aneurysm which was coiled. The patient required insertion of external ventricular drainage during which $10 \mathrm{~mL}$ of cerebrospinal fluid was collected for the analysis. The material was characterized: blood stained with opalescent transparency; white cell count (WCC) - 118/ $\mu \mathrm{L}$; red blood cell count (RBC) - 20000/ $\mu \mathrm{L}$; protein concentration - $1944 \mathrm{mg} /$ $\mathrm{dL}$. The blood in the ventricles was gradually absorbed and patient's condition improved. After 14th day the patient was woken up and the ventricular drainage was removed. Control case was admitted with six months history of gait disturbance, urinary incontinence and mental decline. The patient was diagnosed with the normal pressure hydrocephalus (Figure 2 ) and the programmable ventriculo-peritoneal shunt (Sophy Mini SM8 valve, Sophysa) was inserted where $10 \mathrm{~mL}$ of cerebrospinal fluid was collected. The material was characterized: colorless with clear transparency; white cell count (WCC) - $2 / \mu \mathrm{L}$; red blood cell count (RBC) - 320/ $\mu \mathrm{L}$; protein concentration - $166 \mathrm{mg} / \mathrm{dL}$. The neurological condition of the case gradually improved after the operation. Immediately after collection of cerebrospinal fluid, the material was centrifuged at $3000 \mathrm{rpm}$ for $10 \mathrm{~min}$ and stored at $-80^{\circ} \mathrm{C}$ until analyzed.

\section{Isoelectric focusing fractionation}

Prior the fractionation, the filter membrane Amicon Ultra 100K (Millipore, Bedford, MA) devices were used for ultrafiltration procedure to cut off the high molecular weight proteins, according to the manufacturer's instructions [20]. Firstly, the membrane was rinsed with deionized water, then $2000 \mu \mathrm{L}$ of cerebrospinal fluid was centrifuged at $5400 \times \mathrm{g}$ for $30 \mathrm{~min}$. The collected filtrate was mixed with n-octylglucoside to a concentra- 


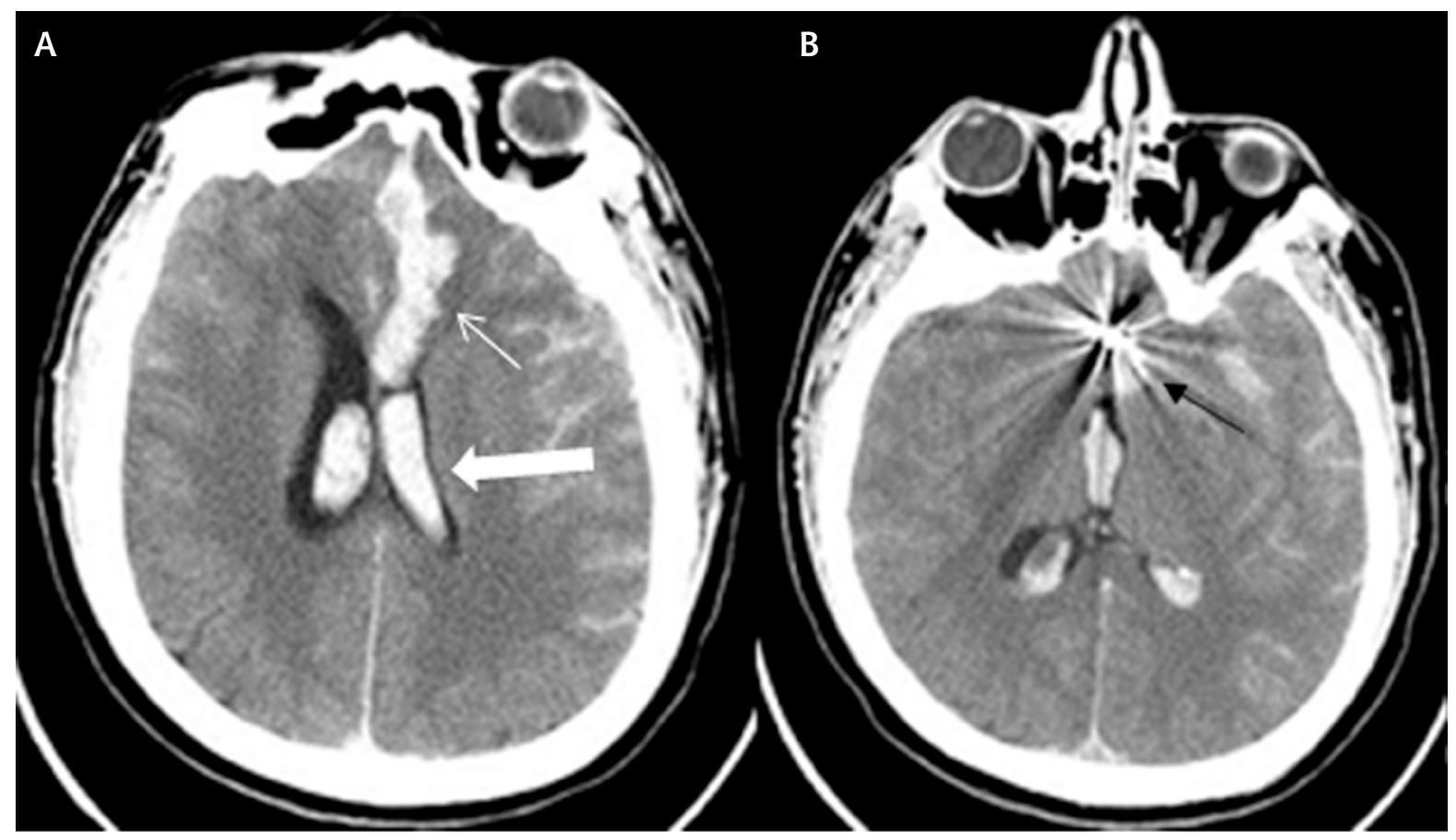

Figure 1. A computed tomography (CT) scan of the patient with subarachnoid hemorrhage on admission demonstrating: (A) intracerebral hemorrhage (white thin arrow) with intraventricular extension (white thick arrow); (B) coiled aneurysm of anterior communicating artery and the blood in fourth ventricle (black arrow)

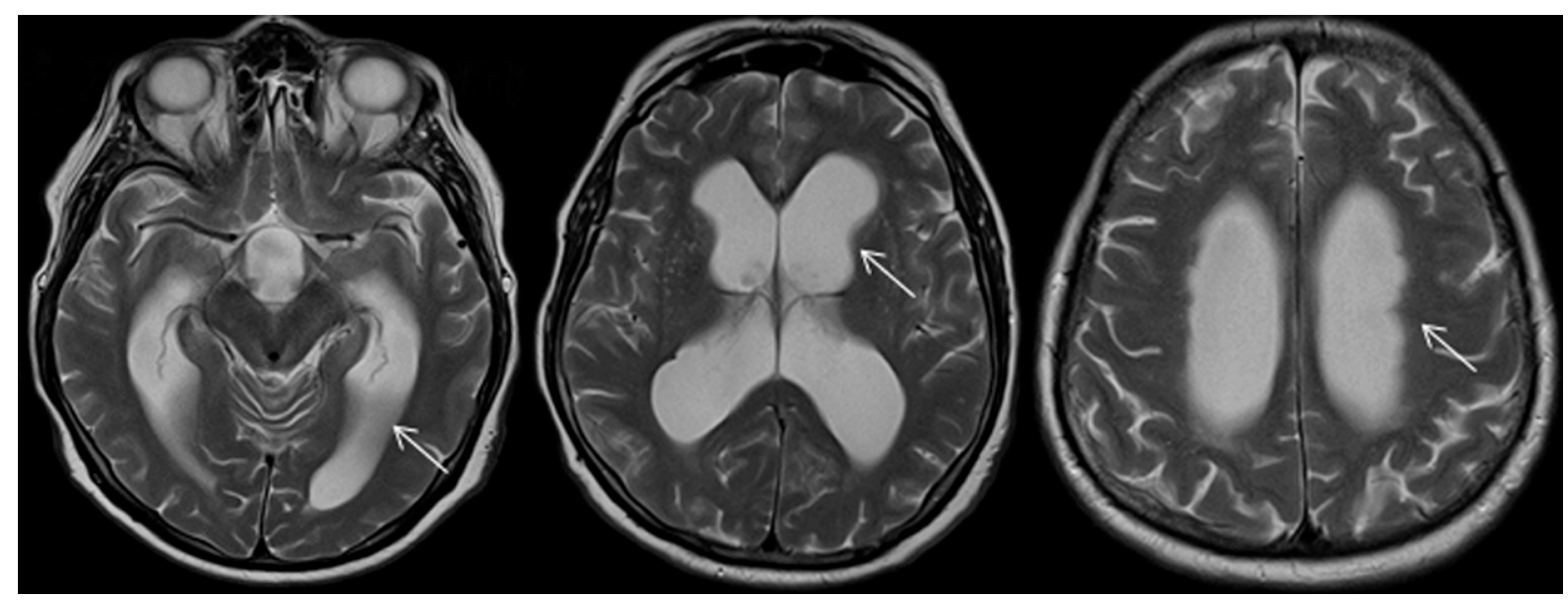

Figure 2. A magnetic resonance imaging (MRI) of the control patient with normal pressure hydrocephalus demonstrating dilated ventricles (white thin arrow)

tion of $0.1 \%$ and with ampholyte $(40 \%$, $\mathrm{pH}$ range $3-10$ isodalt, Bio-Lyte, Biorad) to a concentration of $2.5 \%$. The $500 \mu \mathrm{g}$ of CSF protein was loaded into the MicroRotofor chamber (Bio-Rad Laboratories, Hercules, CA, USA) for focusing without further treatment. Constant power (1 W) was applied. Initial voltage was approximately $80 \mathrm{~V}$ and a plateau of $600 \mathrm{~V}$ was reached after $2 \mathrm{~h}$. Ten separate fractions for each investigated case were rapidly harvested and purified using ReadyPrep 2-D (Bio-Rad Laboratories, Hercules, CA, USA) cleanup kit in accordance to manufacturer's instruction [21]. The precipitated proteins were resolved in 30\% ACN/0.1\%
TFA solution and subjected to MALDI-TOF/TOF-MS/MS analysis acquiring gel free and SDS-PAGE strategies.

\section{Gel electrophoresis}

Additionally, the IEF fractions from SAH case were separated using SDS-PAGE. The $20 \mu \mathrm{L}$ of sample mixture was loaded on a $14 \%$ Tris-glycine-SDS-PAGE gel and the process was carried out at $200 \mathrm{~V}$ for $40 \mathrm{~min}$. Gel separation was performed on a Mini-Protean Tetra Cell (Bio-Rad Laboratories, Hercules, CA, USA) and was continued until the blue bromophenol front reached the bottom of the gels. The gel was stained with Coomas- 
sie Brilliant Blue G250 and the background was washed out by use of $9 \%$ acetic acid.

In-gel and In-solution digestion

All in-solution CSF fractions obtained from MicroRotofor were subjected to digestion protocol according to the procedure modified from Pierce In-Solution Tryptic Digestion Kit. While the most intense proteins bands in the mass range from 20 to $37 \mathrm{kDa}$ of Coomassie stained gel were processed with in-gel digestion according to adopted Shevchenko et al. protocol [22], the digested peptides were extracted from the gel by incubation in $50 \mu \mathrm{L}$ of $50 \%$ ACN/ $0.1 \%$ TFA solution.

\section{MALDI-TOF/TOF-MS/MS protein identification}

The digested peptides were subjected to nano-LC analysis. The system consisted of EASY nano-LC II (Bruker Daltonics) and fraction collector Proteineer-fc II (Bruker Daltonics). Firstly, loaded peptides were concentrated on a trap column NS-MP-10 BioSphere C18 $5 \mu \mathrm{m}$ particle size, $120-\AA ̊$ pore size, $100 \mu \mathrm{m}$ inner diameter, $20 \mathrm{~mm}$ length (NanoSeparations, Nieuwkoop, Netherlands), then separated on a Acclaim PepMap 100 column C18, $3 \mu \mathrm{m}, 100 \AA, 75 \mu \mathrm{m} \times 150 \mathrm{~mm}$ (Thermo Scientific, Sunnyvale, CA, USA) by linear gradient of water (mobile phase A) and 90\% ACN (mobile phase B), both containing $0.05 \%$ TFA. The gradient elution method was: $2-50 \%$ B in 96 min. The flow rate was maintained at $300 \mathrm{~nL}$ min-1 and the injection volume was $6 \mu \mathrm{L}$. In total, 384 fractions of each separated fraction were automatically mixed with matrix solution and spotted onto a AnchorChipTM target (Bruker Daltonics). Per fraction $80 \mathrm{nl}$ of eluent was mixed with $420 \mathrm{nl}$ matrix solution. Matrix solution was generated by mixing: 748 $\mu \mathrm{L}$ of 95:5 (v/v) acetonitrile: 0.1\% TFA, $36 \mu \mathrm{L}$ of saturated solution of HCCA in 90:10 (v/v) acetonitrile:0.1\% TFA, $8 \mu \mathrm{L}$ of $10 \%$ TFA and $8 \mu \mathrm{L}$ of $100 \mathrm{mM}$ ammonium phosphate monobasic. The system was controlled using HyStar 3.2 software (Bruker Daltonics). Afterwards, the tandem mass spectrometry analysis was performed using the MALDI-ToF/ToF UltrafleXtreme instrument equipped with a SmartBeam II laser (Bruker Daltonics). Typical instrument setting for MS mode was as follows: ion source 1, $25.09 \mathrm{kV}$; ion source 2, $22.59 \mathrm{kV}$; lens voltage, $7.89 \mathrm{kV}$; pulsed ion extraction time, $120 \mathrm{~ns}$; matrix suppression mass cut off, $\mathrm{m} / \mathrm{z} 700$. All spectra were acquired by accumulating 4000 shots from 40 non-overlapping positions with a repetition rate of the pulsed laser of $2 \mathrm{kHz}$. By routine, a standard peptide calibration mixture in the mass range of $700-3500$ Da (Bruker Daltonics) was analyzed for external cali- bration of the mass spectrometer. The MS/MS mode for protein identification was applied with the following setting: ion source $1,7.50 \mathrm{kV}$; ion source $2,6.75$ $\mathrm{kV}$; lens, $3.50 \mathrm{kV}$; reflectron 1, $29.50 \mathrm{kV}$; reflectron 2, 14.00; lift 1, $19.00 \mathrm{kV}$; lift 2, $3.00 \mathrm{kV}$, pulsed ion extraction time, $80 \mathrm{~ns}$; fragments only. Precursors with a signal-to-noise ratio above 10 were automatically subjected to MS/MS analysis. The maximum number of MS/MS per fraction was set to 20 . The control of the instrument, data acquisition, processing and evaluation was performed using the following software platforms: flexControl 3.4, FlexAnalysis 3.4 and WARP-LC 1.3 and ProteinScape 3.1 (Bruker Daltonics). The MS/ MS spectra were processed with ProteinScape 3.0 platform by searching the SwissProt database with Mascot 2.4.0 search engine (Matrix Science, London, UK). The LC-MALDI results were filtered to a false discovery rate at a peptide-spectrum match level of less than $1 \%$ based on decoy counts and only proteins with at least one unique peptide were included. The LC-MALDI data were used with the significant threshold of $p>0.05$ set by the search engine. The general protein search parameters were included: trypsin and semi trypsin digestion, 1 and 2 missed cleavages, peptide precursor mass tolerance: $35 \mathrm{ppm}$; fragment mass tolerance: 0.7 Da; peptide charge: +1 ; monoisotopic mass; carbamidomethylation of cysteine as fixed modification; oxidation and dioxidation of methionine as variable modification. The results were compiled into one protein list.

\section{Statistical analysis}

The interpretation of isoelectric focusing separation was performed by intersection analysis of two items between groups of ten fractions, which contained measured masses of peptides obtained by $\mathrm{nLC}-\mathrm{MAL}$ DI-TOF/TOF-MS/MS. The 45 selections of interaction (as a result of combination of two items choose ten fractions) were showed as an upper triangular image plot. For clarity, the symmetrical lower triangular part was presented as a blackened area. The cumulative intersection analysis was made in both left and right directions starting from the fifth fraction, as a point of injection of the sample. We define $m \in\{1,2, \ldots 10\}$ $\{5\}$, as a number of fraction and $n=5$ (fifth fraction). Therefore, $\mathrm{Lm}$ a result for $\mathrm{m}$ fractions can be presented using following notations:

$$
\bigcap_{n=5}^{n-m}=L_{m}
$$

for the left direction and

$$
\bigcap_{n=5}^{m-n}=L_{m}
$$


for right one. Furthermore, the membership of set was created by using of all peptides included by search engine to identify two proteins: peroxiredoxin- 6 and cathepsin B, which were described as potential indicators for this brain pathology and had enough number of peptide to analyze. For all steps, MATLAB v.8.1.0.604 software with the Bioinformatics Toolbox was used.

\section{Results}

\section{Gel-free LC-MS/MS approach}

Using gel free approach consisting of the LP-IEF set and nLC-MALDI-TOF/TOF-MS/MS, the CSF digested peptides derived from patient with and without $\mathrm{SAH}$ were analyzed. The data dependent acquisition (DDA) mode was acquired, where full-scan MS analysis was performed and subsequently MS/MS fragmentation on a defined number of the most intense ions. The approach is valuable in the untargeted investigation of samples with no hypothesis about which parent ions should be fragmented as a priority. The identified proteins and peptides from the different fractions were collected into compilation list. In total, 1664 and 2187 unique tryptic peptides provided biological evidence for 134 and 271 proteins in control and SAH sample, respectively (Supplementary material 1 and 2). Among these the characteristic of high abundant components of CSF were acknowledged. Due to high dynamic range between analyzed samples, in CSF with SAH up to 177 unique proteins were recognized. The data obtained from particular IFE fractions of SAH specimen were compared. The highest identification number was found in fraction 5, where from 167 detected proteins as many as 67 were unique. Further, the fraction 4, 8 and 7 also gave valuable contribution to proteomic characterization of the analyzed case, whereas fraction 1, 2 and 10 presented poor description in protein content. Analyzing the specificity of separation process, it was observed that many common species were overlapping with the neighboring fractions. The $\mathrm{pl}$ of detected proteins were varying from 3.9 to 16.4. Thus, in overall distribution of biomolecules in artificial pH gradient (Figure 3), we were able to observe higher repletion of proteins with pl 5-6 in IEF fraction 3, 4 and 5, whereas the proteins with pl 8-9 were more abundant in the last fractions. The interaction analysis of masses identified by MALDI-TOF/TOF-MS/MS between two selected fractions was shown as the upper triangular image plot

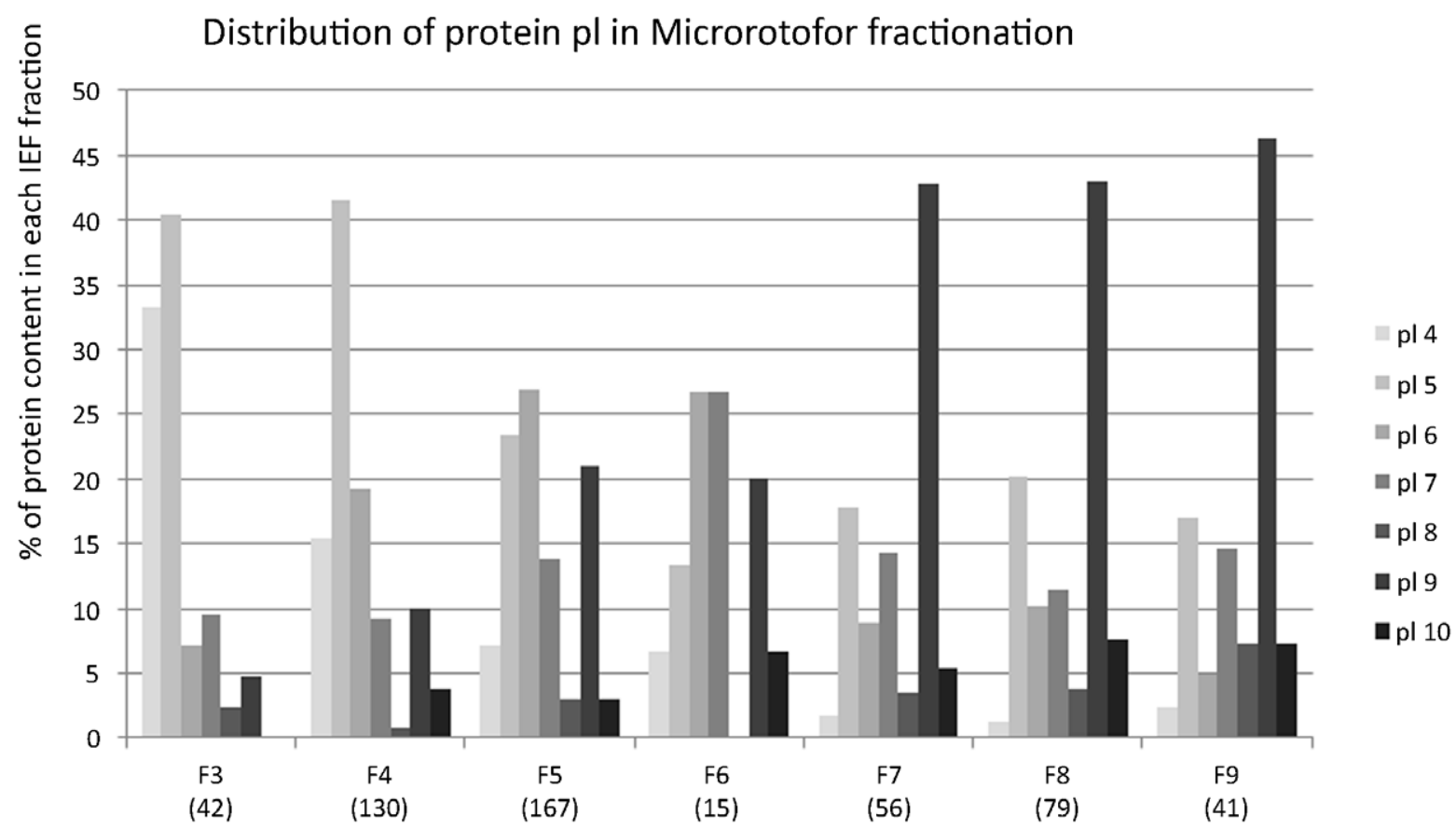

Fraction 3 - 9 in MicroRotofor separation (total number of identified proteins)

Figure 3. A bar graph represents the distribution of protein isoelectric point (pl) in Microrotofor separation between fractions 3 to 9 . On the horizontal axis the investigated fractions and identified per each proteins with the percentage content according to its $\mathrm{pl}$ 


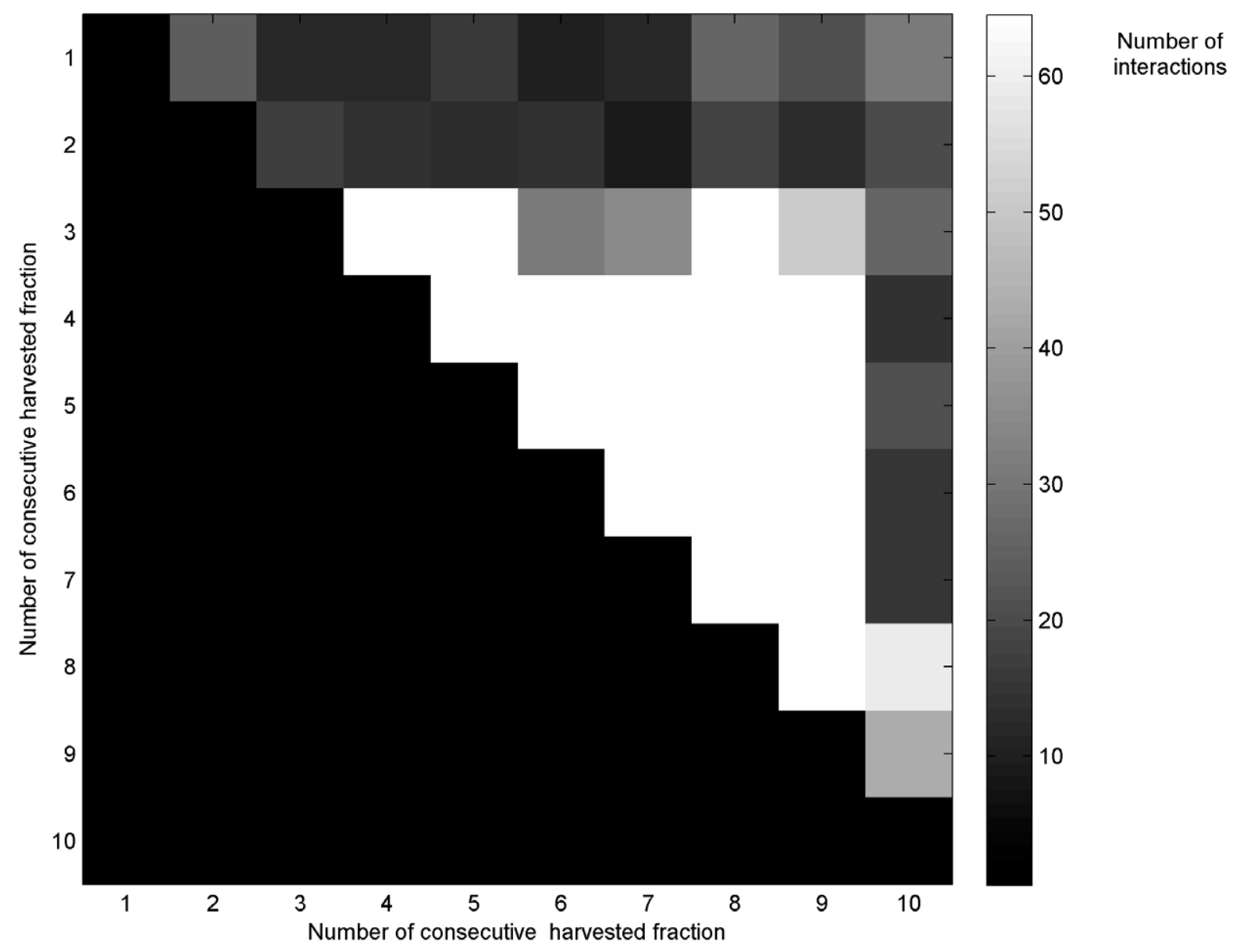

Figure 4. Upper triangular image plot of cumulative intersection analysis of two items in group of ten fractions. For clarity symmetrical lower triangular part was presented as a blackened area

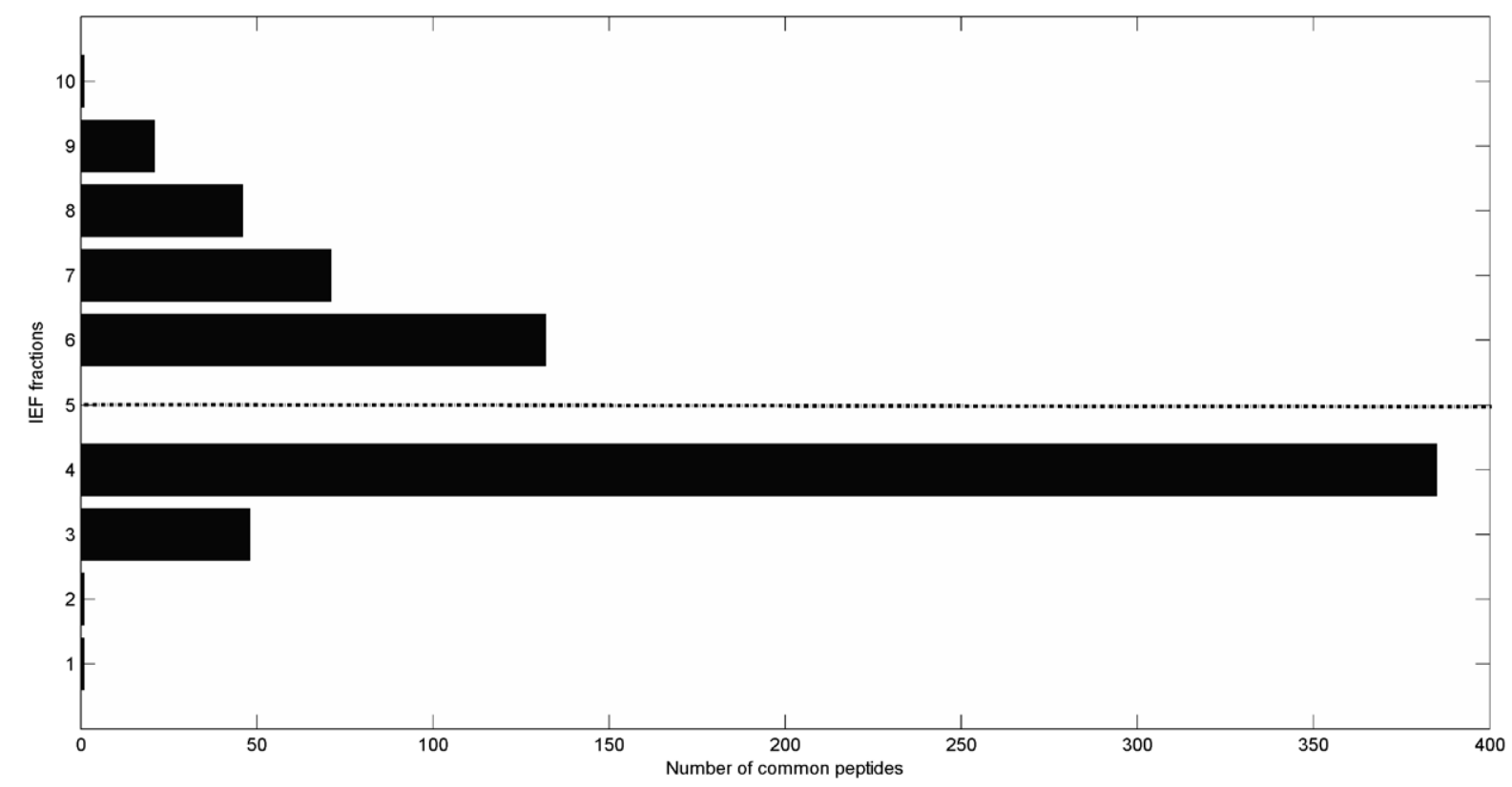

Figure 5. Cumulative intersection analysis for all measured compounds 
(Figure 4). The intersection analysis of two items in group of ten fractions resulted in 45 compared areas. The performed analysis indicated a large number of common compounds in the adjacent fractions, especially true for the fractions in the center. Moreover, it was noticed that larger distance between the fractions ensured the identification of more unique elements. The best separation performance was obtained between pairs of 1-6 and 2-7. The highest concentration of the detected components was observed in the middle fractions, whereas the gradual dilution appeared on the extremes of the MicroRotofor chamber. The dilution process occurred better in the left direction from the center. This effect is clearly seen in Figure 5, which shows the cumulative intersection of the fractions starting from the fraction number 5 in the decreasing direction on the left and increasing on the right. Regarding to the quantity, the fractions are not arranged symmetrically with respect to a fraction number 5 . The total number of all detected compounds (included peptides) were the highest in fraction 4 (2995) and 5 (3667). Although, some of their measured masses were presented also in other fractions (Figure 6), which is confirmation for dilution phenomenon. The Figure 6 shows the membership of the peptides masses used for identification of chosen proteins: cathepsin $B$ and peroxiredoxin- 6 . The measured $\mathrm{m} / \mathrm{z}$ of enzyme protease cathepsin $B$ were additionally observed in fraction 2, 3, 7 and 8. With regard to protein peroxiredoxin- 6 a similar conclusion was proposed. The characteristic masses assigned to this protein have been detected in the whole range of analyzed fractions.

\section{Gel-based LC-MS/MS approach}

The most intense protein bands in the mass range from 20 to $37 \mathrm{kD}$ from SDS-PAGE analysis were excised from the gel and subjected into in-gel digestion procedure (Supplementary material 3). The common identified proteins in both strategies (SDS-PAGE vs gel free) were compared with respect to percentage of sequence coverage and number of identified tryptic peptides (Table 1). We observed that approximately $80 \%$ of the analyzed proteins was better characterized using gel free strategy, thus we concluded that this methodology is valuable in screening analysis of various biological samples.

\section{Discussion}

In our study we implemented the LP-IEF based on distribution of current via the electrolytes system gradually increasing $\mathrm{pH}$ from anode to cathode. The principle underlies in placement of proteins and others components between both electrodes where the $\mathrm{pH}$ is equal with the isoelectric point of analyzed molecules. However, it is difficult to predict or achieve the optimal length of focusing run. Moreover, the separation of all components in $\mathrm{pH}$ gradients should be perceived more as a quasi-equilibrium process [23]. The Rotofor

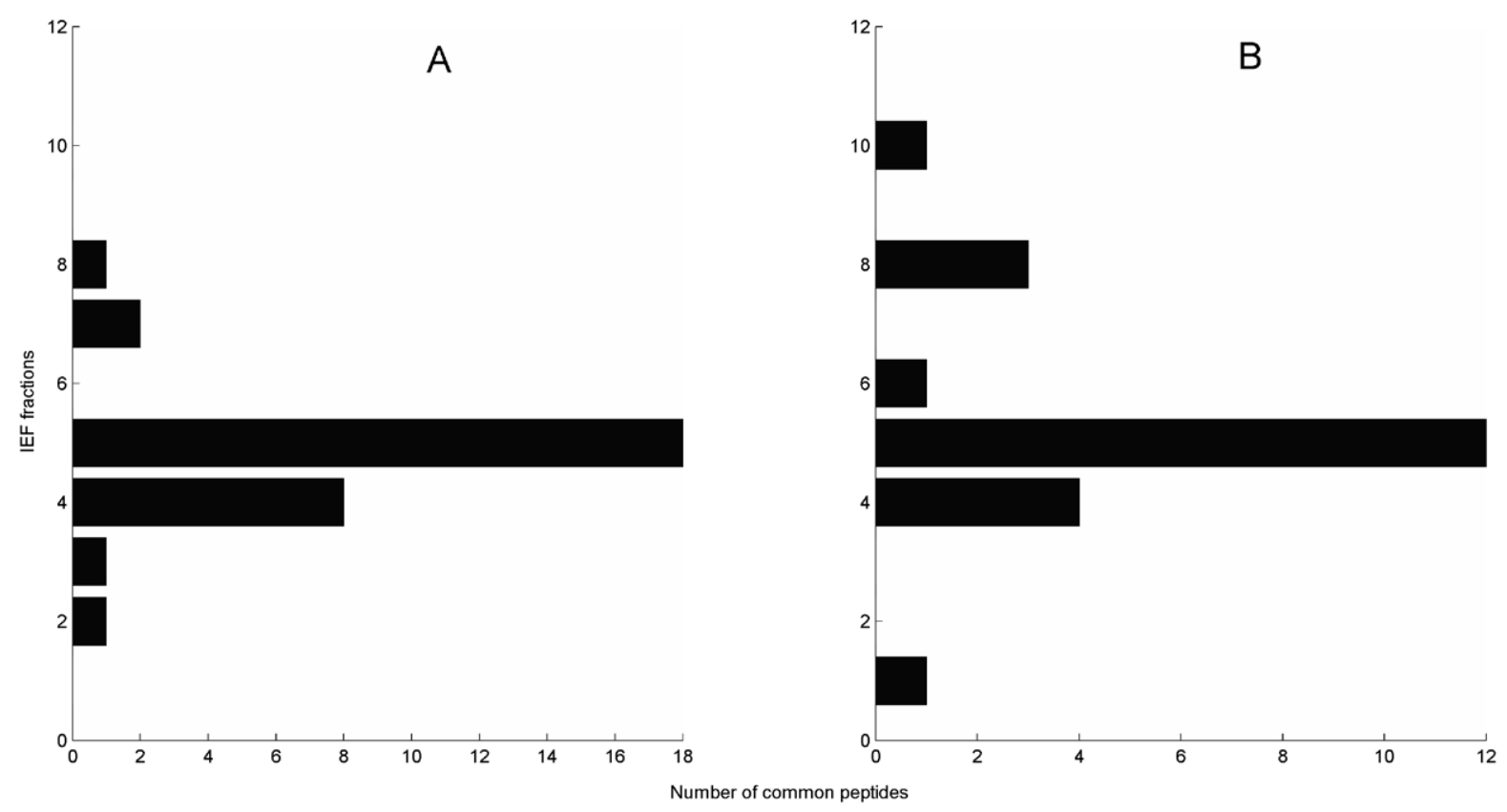

Figure 6. The membership of the detected peptides used for identification of protein cathepsin $B(A)$ and peroxiredoxin-6 (B) in particular IEF fractions 
Table 1. The common proteins and peptides identified in cerebrospinal fluid with subarachnoid hemorrhage using MALDI gel free and SDS-PAGE approach. The comparison based on number of identified tryptic peptides and obtained sequence coverage (SC)

\begin{tabular}{|c|c|c|c|c|c|c|c|}
\hline No. & Accession & Protein name & $\begin{array}{l}\mathrm{MW} \\
{[\mathrm{kDa}]}\end{array}$ & $\begin{array}{l}\text { Peptides } \\
\text { SDS-PAGE }\end{array}$ & $\begin{array}{l}\text { Peptides } \\
\text { gel free }\end{array}$ & $\begin{array}{l}\text { SC [\%] } \\
\text { SDS-PAGE }\end{array}$ & $\begin{array}{l}\text { SC [\%] } \\
\text { gel free }\end{array}$ \\
\hline 1 & APOA1_HUMAN & Apolipoprotein A-I & 30.8 & 6 & 19 & 33.7 & 61.8 \\
\hline 2 & B2MG_HUMAN & Beta-2-microglobulin & 13.7 & 4 & 19 & 46.2 & 63.9 \\
\hline 3 & PMGE_HUMAN & Bisphosphoglycerate mutase & 30.0 & 2 & 6 & 16.2 & 32.4 \\
\hline 4 & CAH1_HUMAN & Carbonic anhydrase 1 & 28.9 & 66 & 54 & 80.1 & 86.2 \\
\hline 5 & CAH2_HUMAN & Carbonic anhydrase 2 & 29.2 & 28 & 30 & 68.8 & 68.5 \\
\hline 6 & CAH3_HUMAN & Carbonic anhydrase 3 & 29.5 & 5 & 7 & 42.7 & 41.9 \\
\hline 7 & COTL1_HUMAN & Coactosin-like protein & 15.9 & 2 & 3 & 27.5 & 35.2 \\
\hline 8 & COF1_HUMAN & Cofilin-1 & 18.5 & 2 & 10 & 28.9 & 66.3 \\
\hline 9 & DOPD_HUMAN & D-dopachrome decarboxylase & 12.7 & 3 & 3 & 28.0 & 30.5 \\
\hline 10 & HEM2_HUMAN & Delta-aminolevulinic acid dehydratase & 36.3 & 2 & 3 & 12.1 & 16.1 \\
\hline 11 & NPC2_HUMAN & Epididymal secretory protein E1 & 16.6 & 2 & 2 & 17.9 & 25.8 \\
\hline 12 & BLVRB_HUMAN & Flavin reductase (NADPH) & 22.1 & 19 & 15 & 60.2 & 63.6 \\
\hline 13 & GST01_HUMAN & Glutathione S-transferase omega-1 & 27.5 & 7 & 10 & 34.9 & 33.2 \\
\hline 14 & G3P_HUMAN & Glyceraldehyde-3-phosphate dehydrogenase & 36.0 & 10 & 9 & 40.6 & 34.3 \\
\hline 15 & HEMO_HUMAN & Hemopexin & 51.6 & 2 & 17 & 8.7 & 46.1 \\
\hline 16 & IGHA2_HUMAN & Ig alpha-2 chain C region & 36.5 & 2 & 11 & 7.9 & 42.1 \\
\hline 17 & IGHGI_HUMAN & Ig gamma-1 chain $C$ region & 36.1 & 4 & 26 & 24.2 & 61.8 \\
\hline 18 & IGKC_HUMAN & Ig kappa chain C region & 11.6 & 6 & 7 & 80.2 & 80.2 \\
\hline 19 & LAC3_HUMAN & Ig lambda-3 chain $\mathrm{C}$ regions & 11.2 & 4 & 3 & 55.7 & 46.2 \\
\hline 20 & IBP7_HUMAN & Insulin-like growth factor-binding protein 7 & 29.1 & 3 & 12 & 21.6 & 55.3 \\
\hline 21 & KLK6_HUMAN & Kallikrein-6 & 26.8 & 3 & 5 & 23.4 & 33.2 \\
\hline 22 & LXN_HUMAN & Latexin & 25.7 & 2 & 2 & 9.5 & 12.2 \\
\hline 23 & PPAC_HUMAN & $\begin{array}{l}\text { Low molecular weight phosphotyrosine protein } \\
\text { phosphatase }\end{array}$ & 18.0 & 3 & 4 & 35.4 & 43.7 \\
\hline 24 & TIMP1_HUMAN & Metalloproteinase inhibitor 1 & 23.2 & 3 & 9 & 15.5 & 67.1 \\
\hline 25 & PPIA_HUMAN & Peptidyl-prolyl cis-trans isomerase A & 18.0 & 3 & 19 & 24.8 & 70.9 \\
\hline 26 & PRDX2_HUMAN & Peroxiredoxin-2 & 21.9 & 15 & 14 & 58.1 & 76.8 \\
\hline 27 & PRDX6_HUMAN & Peroxiredoxin-6 & 25.0 & 9 & 14 & 47.8 & 67.4 \\
\hline 28 & PEBP1_HUMAN & Phosphatidylethanolamine-binding protein 1 & 21.0 & 3 & 14 & 34.8 & 79.7 \\
\hline 29 & PTGDS_HUMAN & Prostaglandin-H2 D-isomerase & 21.0 & 7 & 22 & 46.8 & 74.7 \\
\hline 30 & PARK7_HUMAN & Protein DJ-1 & 19.9 & 4 & 17 & 30.7 & 65.1 \\
\hline 31 & PNPH_HUMAN & Purine nucleoside phosphorylase & 32.1 & 12 & 12 & 40.1 & 50.9 \\
\hline 32 & TRFE_HUMAN & Serotransferrin & 77.0 & 2 & 67 & 3.9 & 69.8 \\
\hline 33 & ALBU_HUMAN & Serum albumin & 69.3 & 11 & 126 & 18.1 & 85.7 \\
\hline 34 & SODC_HUMAN & Superoxide dismutase [Cu-Zn] & 15.9 & 4 & 9 & 38.3 & 64.9 \\
\hline 35 & TTHY_HUMAN & Transthyretin & 15.9 & 38 & 18 & 86.4 & 69.4 \\
\hline 36 & TPIS_HUMAN & Triosephosphate isomerase & 30.8 & 13 & 15 & 65.7 & 71.0 \\
\hline
\end{tabular}

separation has no barriers and it is common that the same proteins can be found in several focused fractions, causing the fractionation less sufficient [24]. In our study the effectiveness of the IEF fractionation was assessed with combination of direct MALDI analysis. For MS analysis the computer-controlled data dependent acquisition mode related to ion abundance levels in analyzed sample was used. The ions selection for MS/ MS analysis is associated with the width of the chromatographic peaks or with the concentration of peptides comprised in complex mixtures. In biological fluids the number of peptides co-eluting can considerably exceed the number of ions subjected for MS/MS acquisition. Therefore, the data acquisition can be biased against the low abundance signals that corresponded to proteins at low concentration. Also if the ionization technique favors certain peptide features, then ions section is determined towards those ions. Thus, more concentrated proteins will be selected, reflecting the abundance level in sample as the peptide hits and spectral count correlated to protein abundance [25]. Regarding to our results, the identified proteins were presented mostly in higher concentration as neither immunodepletion methods nor combination with additional chro- 
Table 2. The identified proteins with potential value as biomarkers in cerebrospinal fluid after subarachnoid hemorrhage using gel free nLC-MALDI-TOF/ TOF-MS/MS mass spectrometry approach

\begin{tabular}{|c|c|c|c|c|c|}
\hline Accession & Protein name & Score & $\mathrm{SC} \%$ & $\mathrm{~m} / \mathrm{z}$ meas. & Peptide Sequence \\
\hline $\begin{array}{l}\text { PRDX6 } \\
\text { HUMAN }\end{array}$ & Peroxiredoxin-6 & 813.62 & 67.40 & $\begin{array}{l}2098.1237 \\
2030.9957 \\
1395.6609 \\
1897.0140 \\
1582.6731 \\
1085.6053 \\
1900.9822 \\
1884.9907 \\
1135.6600 \\
1191.6760 \\
906.4737 \\
1829.8861 \\
1007.5473 \\
915.4934\end{array}$ & $\begin{array}{l}\text { M.PGGLLLGDVAPNFEANTTVGR.I R.FHDFLGDSWGILFSHPR.D } \\
\text { R.DFTPVCTTELGR.A K.LIALSIDSVEDHLAWSK.D } \\
\text { K.DINAYNCEEPTEK.L } \\
\text { K.LPFPIIDDR.N } \\
\text { R.ELAILLGMLDPAEKDEK.G + Oxidation } \\
\text { R.ELAILLGMLDPAEKDEK.G } \\
\text { R.VVFVFGPKK.L } \\
\text { K.LSILYPATTGR.N } \\
\text { R.NFDEILR.V } \\
\text { K.DGDSVMVLPTIPEEEAK.K } \\
\text { R.VVFVFGPK.K } \\
\text { R.VATPVDWK.D }\end{array}$ \\
\hline PENK_HUMAN & Proenkephalin A & 294.4 & 14.2 & $\begin{array}{l}2222.0680 \\
1853.8109 \\
2125.1529 \\
1528.8011\end{array}$ & $\begin{array}{l}\text { R.LVRPADINFLACVMECEGK.L } \\
\text { R.PADINFLACVMECEGK.L } \\
\text { K.ELLQLSKPELPQDGTSTLR.E } \\
\text { L.SKPELPQDGTSTLR.E }\end{array}$ \\
\hline TSP1_HUMAN & Thrombospondin-1 & 74.11 & 2.80 & $\begin{array}{l}2195.0619 \\
1394.7346 \\
\end{array}$ & $\begin{array}{l}\text { R.IPESGGDNSVFDIFELTGAAR.K } \\
\text { R.FVFGTTPEDILR.N }\end{array}$ \\
\hline GFAP_HUMAN & $\begin{array}{l}\text { Glial fibrillary acidic } \\
\text { protein }\end{array}$ & 139.3 & 10.9 & $\begin{array}{l}1098.6294 \\
1215.6248 \\
1263.6353 \\
\end{array}$ & $\begin{array}{l}\text { K.ALAAELNQLR.A R.DNLAQDLATVR.Q } \\
\text { R.LEAENNLAAYR.Q }\end{array}$ \\
\hline $\begin{array}{l}\text { SPTA1_ } \\
\text { HUMAN }\end{array}$ & $\begin{array}{l}\text { Spectrin alpha chain, } \\
\text { erythrocyte }\end{array}$ & 129.9 & 2.2 & $\begin{array}{l}1468.8693 \\
1667.7788 \\
\end{array}$ & $\begin{array}{l}\text { Y.GRDLQGVQNLLKK.H } \\
\text { K.HEALENDFAVHETR.V }\end{array}$ \\
\hline CATB_HUMAN & Cathepsin B & 1413.4 & 54.9 & $\begin{array}{c}2102.0655 \\
1858.9369 \\
1527.8217 \\
982.4931 \\
1855.9301 \\
1839.9336 \\
1286.6291 \\
2172.9245 \\
1590.7879 \\
1850.8756 \\
1314.6047 \\
1634.7256 \\
2005.9942 \\
1589.6918 \\
1945.9297 \\
1929.9390 \\
1573.6741 \\
1823.8596 \\
876.4665\end{array}$ & $\begin{array}{l}\text { R.SRPSFHPLSDELVNYVNK.R } \\
\text { R.PSFHPLSDELVNYVNK.R } \\
\text { R.LCGTFLGGPKPPQR.V } \\
\text { R.VMFTEDLK.L } \\
\text { R.VMFTEDLKLPASFDAR.E } \\
\text { R.VMFTEDLKLPASFDAR.E } \\
\text { R.EQWPQCPTIK.E } \\
\text { R.DQGSCGSCWAFGAVEAISDR.I K.GLVSGGLYESHVGCR.P } \\
\text { K.GLVSGGLYESHVGCRPY.S } \\
\text { K.ICEPGYSPTYK.Q } \\
\text { K.HYGYNSYSVSNSEK.D } \\
\text { K.NGPVEGAFSVYSDFLLYK.S } \\
\text { K.SGVYQHVTGEMMGGH.A K.SGVYQHVTGEMMGGHAIR.I K. } \\
\text { SGVYQHVTGEMMGGHAIR.I N.SWNTDWGDNGFFK.I R. } \\
\text { GQDHCGIESEVVAGIPR.T } \\
\text { K.LPASFDAR.E }\end{array}$ \\
\hline
\end{tabular}

matographic columns (i.e. weak cation exchange chromatography) were applied to overcome the problem of protein dynamic range concentration. Moreover, keeping in mind that blood contamination directly disturbs the detailed proteome investigation; our goal was to show the current state of the protein composition during the SAH. The extensive data obtained from MALDI analysis contribute much to overall screening of the analyzed material, pointing the protein abundance of in this brain pathology. However, not all of the collected MS/MS spectra were correctly assigned to sequence database. The reason could be seeing that in complex mixtures the majority of confidently identified peptides are based on tryptic ends [26]. Thus, limits of this approach can be related to digestion process which increased sample complexity [27].

In the recent studies few reports were published describing SAH as a neuropathology complication that significantly increased mortalities of the cases. Despite rapid hospitalization, the treatment outcome is difficult to predict. Therefore, the biomarkers of SAH are needed to improve knowledge about this condition and to 
monitor all changes occurring in the central nervous system. From our protein identification list we were able to recognize proteins which were already recognized as potential indicators by other groups (Table 2). Proenkephalin A, a stable precursor fragment of the encephalin, was detected in our study based on four peptides. It was reported that high level of plasma proenkephalin A was associated with poor clinical outcome of aneurysmal SAH and might carry predictive value for 6-month mortality $[4,28]$. Further, the glutathione S-transferase P (GSTP1) and peroxiredoxin- 6 (PRDX6) significant increases were observed in extracellular microdialysate of stroke patients [29]. By using MALDI proteomic approach we were able to identify the peroxiredoxin- 6 with $67.4 \%$ sequence coverage. Additionally, the protein cathepsin B was also recognized with high sequence coverage on the level of $54.9 \%$. Interestingly, it was highlighted by Yu et al. that cathepsin B/D was up-regulated in the neurons of rat cortexes after $\mathrm{SAH}$ [30]. The time course investigation reveals the expression of cathepsin B/D peaked at 48 $\mathrm{h}$ suggesting that these proteases may be released into neurone cytoplasm after SAH, where the lysosomal iron overload may lead to the activation of the apoptotic signaling. Moreover, three other potential indicators of early brain injury such as thrombospondin-1, glial fibrillary acidic protein and $\alpha$-spectrin were identified. So far they were not analyzed in the CSF of patients with subarachnoid hemorrhage [31]. The thrombospondin-1 is a glycoprotein known to take part in hemostasis and angiogenesis. The increased expression was observed in experimental intracerebral hemorrhage. Consequently, the higher plasma level was also found to be related with clinical severity and long-term prognosis [32]. Further, the glial fibrillary acidic protein (GFAP) a brain specific biomarker is seeking to have diagnostic potential and prognostic value as two experimental studies pointed to higher GFAP levels in serum of patients with greater SAH severity and poorer patient outcomes [33-34]. Lastly, the a-II spectrin breakdown products (SBDPs) released from degenerating neurons, were also proposed and identified in higher level in the CSF with SAH [31].

\section{Perspectives}

The proteomic approach based on liquid phase isoelectric focusing fractionation combined with nLC-MALDI-TOF/ TOF-MS/MS analysis was proposed to characterize CSF with $\mathrm{SAH}$. The cumulative intersection analysis of in-solution sample separation revealed the highest concentra- tion of the detected components in the middle fractions of the focusing chamber with gradual dilution on its extreme. Thus, rather pointing to the MicroRotofor utility as a tool for concentration of complex protein sample than selectively fractionation technique. The employed strategy ensured overall screening of investigated material presenting the proteins abundance in the current state of analysis. Few proteins such as proenkephalin $A$, peroxiredoxin-6, cathepsin B, thrombospondin-1, glial fibrillary acidic protein and $\alpha$-spectrin were recognized as potential indicators, according to literature, pointing to the possibility for their monitoring in further studies as panel of valuable biomarkers. Nevertheless, the main limitation is connected with difficulties in availability of the cerebrospinal fluid in routine collection. Further examination should be conducted in term of quantitative analysis of the proposed proteins with inclusion of different time points during the SAH event.

\section{Acknowledgements}

\section{Conflict of interest statement}

The authors declare no conflict of interest.

\section{Funding sources}

The author Joanna Hajduk acknowledges the support for preparing the PhD thesis from National Science Centre in Poland within the frame of the doctoral scholarship financing based on the decision No. DEC-2015/16/T/NZ7/00033.

\section{References}

1. Yuan X, Desiderio DM. Proteomics analysis of prefractionated human lumbar cerebrospinal fluid. Proteomics. 2005 Feb;5(2):541-550.

2. Huhmer AF, Biringer RG, Amato $H$, et al. Protein analysis in human cerebrospinal fluid: Physiological aspects, current progress and future challenges. Dis Markers. 2006 Dec;22(1-2):3-26.

3. Maurer MH, Haux D, Sakowitz OW, et al. Identification of early markers for symptomatic vasospasm in human cerebral microdialysate after subarachnoid hemorrhage: preliminary results of a proteome-wide screening. J Cereb Blood Flow Metab. 2007 Oct;27(10):1675-1683.

4. Chen XL, Yu BJ, Chen MH. Circulating levels of neuropeptide proenkephalin A predict outcome in patients with aneurysmal subarachnoid hemorrhage. Peptides. 2014 Jun;56:111-115.

5. Kuruppu S, Chou SH, Feske SK, et al. Soluble and catalytically active endothelin converting enzyme- 1 is present in cerebrospinal fluid of subarachnoid hemorrhage patients. Mol Cell Proteomics: MCP. 2014 Apr;13(4):1091-1094.

6. Sokol B, Wozniak A, Jankowski R, et al. HMGB1 Level in Cerebrospinal Fluid as a Marker of Treatment Outcome in Patients with Acute Hydrocephalus Following Aneurysmal Subarachnoid Hemorrhage. J Stroke Cerebrovasc. 2015 Aug;24(8):1897-1904.

7. Steinhoff RF, Karst DJ, Steinebach F, et al. Microarray-based MALDI-TOF mass spectrometry enables moni- 
toring of monoclonal antibody production in batch and perfusion cell cultures. Methods. 2015 Jul;104:33-40.

8. Hajduk J, Matysiak J, Kokot ZJ. Challenges in biomarker discovery with MALDI-TOF MS. Clin Chim Acta. 2016 Jul;458:84-98.

9. Annesley TM. Ion supression in mass spectrometry. Clin Chem. 2003 Jul;49(7):1041-1044.

10. Rabilloud T, Chevallet M, Luche $S$, et al. Two-dimensional gel electrophoresis in proteomics: Past, present and future. J Proteomics. 2010 Oct;73(11):2064-2077.

11. Beranova-Giorgianni S. Proteome analysis by two-dimensional gel electrophoresis and mass spectrometry: strengths and limitations. Trac-Trend Anal Chem. 2003 May;22(5):273-281.

12. Michel PE, Reymond F, Arnaud IL, et al. Protein fractionation in a multicompartment device using Off-Gel (TM) isoelectric focusing. Electrophoresis. 2003 Jan;24(1-2):3-11.

13. Tomas R, Yan LS, Krenkova J, et al. Autofocusing and ESI-MS analysis of protein digests in a miniaturized multicompartment electrolyzer. Electrophoresis. 2007 Jul;28(13):2283-2290.

14. Moreda-Pineiro A, Garcia-Otero N, Bermejo-Barrera P. A review on preparative and semi-preparative offgel electrophoresis for multidimensional protein/peptide assessment. Anal Chim Acta. 2014 Jul;836:1-17.

15. Wall DB, Kachman MT, Gong SY, et al. Isoelectric focusing nonporous RP HPLC: A two-dimensional liquid-phase separation method for mapping of cellular proteins with identification using MALDI-TOF mass spectrometry. Anal Chem. 2000 Mar;72(6):1099-1111.

16. Righetti PG, Castagna A, Herbert B, et al. How to bring the "unseen" proteome to the limelight via electrophoretic pre-fractionation techniques. Bioscience Rep. 2005 Apr;25(1-2):3-17.

17. Wang HX, Kachman MT, Schwartz DR, et al. A protein molecular weight map of ES2 clear cell ovarian carcinoma cells using a two-dimensional liquid separations/mass mapping technique. Electrophoresis. 2002 Sep;23(18):3168-3181.

18. Hey J, Posch A, Cohen A, et al. Fractionation of complex protein mixtures by liquid-phase isoelectric focusing. Methods Mol Biol. 2008;424:225-239.

19. Davidsson P, Paulson L, Hesse C, et al. Proteome studies of human cerebrospinal fluid and brain tissue using a preparative two-dimensional electophoresis approach prior to mass spectrometry. Proteomics. 2001 Mar;1(3):444-452.

20. Amicon ${ }^{\circledast}$ Ultra-2 Pre-launch Centrifugal Filter Devices for volumes up to $2 \mathrm{~mL}$ User Guide [cited 13.07.2016]. Available from: http://www.biocenter.hu/pdf/amiconultra2.PDF.

21. ReadyPrep ${ }^{\mathrm{TM}}$ 2-D Cleanup Kit Instruction Manual [cited 13.07.2016]. Available from: http://www.bio-rad.com/ webroot/web/pdf/Isr/literature/MS4110143A.pdf.

22. Shevchenko A, Wilm M, Vorm O, et al. Mass spectrometric sequencing of proteins silver-stained polyacrylamide gels. Anal Chem. 1996 Mar;68(5):850-858.

23. Oliveira BM, Coorssen JR, Martins-de-Souza D. 2DE: The Phoenix of Proteomics. J Proteomics. 2014 Jun;104:140150.
24. Shang TQ, Ginter JM, Johnston MV, et al. Carrier ampholyte-free solution isoelectric focusing as a prefractionation method for the proteomic analysis of complex protein mixtures. Electrophoresis. 2003 Jul;24(14):23592368.

25. Liu H, Sadygov RG, Yates JR, 3rd. A model for random sampling and estimation of relative protein abundance in shotgun proteomics. Anal Chem. 2004;76(14):41934201.

26. Elias JE, Haas W, Faherty BK, et al. Comparative evaluation of mass spectrometry platforms used in large-scale proteomics investigations. Nat Methods. 2005 Sep;2(9):667-675.

27. Scherl A. Clinical protein mass spectrometry. Methods. 2015 Jun;81:3-14.

28. Gao JB, Tang WD, Wang X, et al. Prognostic value of neuropeptide proenkephalin $A$ in patients with severe traumatic brain injury. Peptides. 2014 Aug;58:42-46.

29. Manevich Y, Hutchens S, Halushka PV, et al. Peroxiredoxin VI oxidation in cerebrospinal fluid correlates with traumatic brain injury outcome. Free Radic Biol Med. 2014 Jul;72:210-221.

30. Yu ZQ, Jia Y, Chen G. Possible involvement of cathepsin $B / D$ and caspase-3 in deferoxamine-related neuroprotection of early brain injury after subarachnoid haemorrhage in rats. Neuropathol Appl Neurobiol. 2014 Apr;40(3):270-283.

31. Lad SP, Hegen H, Gupta G, et al. Proteomic biomarker discovery in cerebrospinal fluid for cerebral vasospasm following subarachnoid hemorrhage. J Stroke Cerebrovasc Dis. 2012 Jan;21(1):30-41.

32. Shen YF, Wang WH, Yu WH, et al. The prognostic value of plasma thrombospondin-1 concentrations after aneurysmal subarachnoid hemorrhage. Clin Chim Acta. 2015 Aug;448:155-160.

33. Nylen K, Csajbok LZ, Ost M, et al. Serum glial fibrillary acidic protein is related to focal brain injury and outcome after aneurysmal subarachnoid hemorrhage. Stroke. 2007 May;38(5):1489-1494.

34. Dvorak F, Haberer I, Sitzer M, et al. Characterisation of the diagnostic window of serum glial fibrillary acidic protein for the differentiation of intracerebral haemorrhage and ischaemic stroke. Cerebrovac Dis. 2009 Jan;27(1):37-41.

Acceptance for editing: 2016-07-10 Acceptance for publication: 2016-08-26

Correspondence address: Prof. Zenon J. Kokot, PhD Department of Inorganic and Analytical Chemistry Poznan University of Medical Sciences 6 Grunwaldzka Street, 60-780 Poznan, Poland phone: +48 6185466 10, fax: +4861 8546609 email: zkokot@ump.edu.pl 